\title{
Experimental Verification of FEM Simulation of GMAW Bead on Plate Welding
}

Kovanda Karel, Holub Lukáš, Kolařík Ladislav, Kolaříková Marie, Vondrouš Petr

Czech Technical University in Prague, Faculty of Mechanical Engineering, Prague 6, 16607 ,

E-mail: karel.kovanda@fs.cvut.cz

The research focuses on verification of FEM simulation of GMAW bead on plate welding with experimental results. In the program Visual Environment simple FEM simulation of GMAW bead on plate welding on Al alloy EN AW 7022 was created and these simulation data were compared with measured experimental data. To create good FEM model setting of heat source and material parameters are of great importance. To set parameters of heat source measurement of welding parameters, metallographic sample, weld bead and end crater was experimentally done. During experiment, temperature was measured by several thermocouples and measured temperature was compared with simulation data. The difference of measured and simulated data was at maximum only $10^{\circ} \mathrm{C}$ and we can conclude that this result is very good. Simulations that obtain results close to reality are very useful for designing welded constructions. Designing from using precipitation hardenable Al alloys, e.g. series $7 \times x x$, materials prone to softening, when welded, can be thus made easier and safer using simulation software.

Keywords: simulation, thermal field, Visual Environment, GMAW, welding, Al alloy, 7022

\section{Acknowledgement}

Research was supported by grants SGS ČVUT 2010 č. OHK 2-038/10 and FRVŠ G1 611/2011.

\section{References}

[1] TEJC, J. (2007). Možnosti využití počítačové simulace svařování v průmyslové praxi, Konstrukce, 5/2007, 2007, ISSN 1803-8433.

[2] MEŠKO, J., FABIAN, P., HOPKO, A., KOŇAR, R. (2011). Shape of heat source in simulation program SYSWELD using different types of gases and welding methods. In: Strojírenská technologie XVI, 5/2011, 2011, ISSN 1211-4162.

[3] MA, T.; OUDEN, G. (1998). Softening behavior of Al-Zn-Mg alloys due to welding, Materials science and engineering A 266, 1998 Elsevier, p. 198-204

[4] FURBACHER, I.; MACEK, K.; SEIDL, J. a kolektiv (2001). Lexikon technických materiálů, svazek 4., Praha: Verlag Dashöfer, 2001

[5] KOLAŘÍK, L., KOVANDA, K., VÁLOVÁ, M., DUNOVSKÝ, J. (2011). Posouzení vlivu přídavného materiálu na pórovitost svarových spojů při MIG svařování vytvrditelných hliníkových slitin typu AlMgSi. In: Strojírenská technologie XVI, 1/2011, 2011, ISSN 1211-4162.

[6] KOLÁŘ, V. (2009). Svařování hliníku, Podklady pro kurz IWE, ČVUT, 2009, 66 s.

[7] ESAB [online]. 2009 [cit. 2011-06-14]. Svařování a pálení. Dostupné WWW: $<$ http://products.esab.com/Templates/T041.asp?id=131496>.

[8] KOVANDA, K. (2011). Studium precipitačních procesů ve svarovém kovu a tepelně ovlivněné oblasti u vybraných hliníkových slitin, Kritická literární rešerše, ČVUT v Praze, FS, 2011, 17 s.

[9] KOLǍ̌ÍK, L. (2011) Svařitelnost neželezných kovů - Vliv svařování na vytvrditelné slitiny hliníku typu AlMgSi. Disertační práce, ČVUT v Praze, FS, 2011, 185 s.

[10] ORSZÁGH, P., ORSZÁGH, V. (2000). Zváranie MIG/MAG ocelí a neželezných kovov, Bratislava: Polygrafia SAV, 2000. $460 \mathrm{~s}$.

Paper number: M201207

Manuscript of the paper recieved in 2011-12-29. The reviewers of this paper: Assoc. Prof. Ivo Hlavaty, MSc, Ph.D. and Prof. Josef Mesko, MSc., $P h D$. 